\title{
EMOTIONAL ENLIGHTENMENT: AN OPTIMISTIC APPROACH TOWARDS PARENTIFICATION
}

\author{
Salma Qayyum \\ Lecturer, Department of English, \\ National University of Modern Languages (NUML), Islamabad \\ sqayyum@numl.edu.pk \\ Samina Qayyum \\ Lecturer, Department of English, \\ National University of Modern Languages, Islamabad \\ saqyyum@numl.edu.pk \\ Najma Qayyum \\ Lecturer, Department of English, \\ National University of Modern Languages, Islamabad \\ nqayyum@numl.edu.pk
}

\begin{abstract}
Parentification is generally described as a negative phenomenon that deprives a child of his/her childhood overnight. The parentified child faces a flood of expectations for which s/he is not prepared. His/her parents expect him/her to 'automatically' adopt the role of a parent. In Pakistan, parents are the most important pillars in the foundation of the family and if one of them suffers from a long-term sickness, the whole structure falls apart. From the child's perspective, it is extremely painful. S/he not only loses the blessings of previous physical and emotional assistance but also must perform myriads of responsibilities. So, parentification seems to be a negative experience. This article challenges this idea by proving that parentification can be a positive, pleasurable experience. It focuses on the researcher's parentification experience when her mother underwent a stroke. The data collection methods include audio recordings, diary notes and discussions with the doctor. The data analyses focus on the paralinguistic features of the researcher's speech that she had with the research participant. The research outcomes exhibit the special features of the parentified speech. It also suggests that through mental readiness and planning, the potential parentified figure, can make parentification a rewarding experience.
\end{abstract}

Keywords: parentification, empathetic stress, emotional burnout, self-esteem, denial, regression, frigidity.

\section{INTRODUCTION}

Parentification is usually described as a negative phenomenon, depriving a child of its innocence by imposing unwanted duties for which the child is physically or emotionally not ready and burdening it forever causing permanent emotional damage and perversion that is irreparable. The researcher challenges this idea. She firmly believes that parentification is a unique experience. It might be detrimental for the amateurs but can be rewarding, if not all positive, if occurs to someone at a mature age. She has based her thesis on her own 16 years old personal experience of becoming parentified. Parentification is a role-reversal between a parent and a child when a child takes on the role of a parent and the parent adopts the role of an infant. It can be physical or instrumental as well as emotional. Physical Parentification involves looking after the physical needs and Emotional Parentification involves looking after the emotional needs of the parent. Usually, one type of parentification happens to a child. In the researcher's case, both happened at the same time.

The researcher had an experience of becoming parentified at a mature age. She had done her masters in English and had started her job at NUML as a teacher when her mother had a stroke and resultantly, lost her speaking abilities. Gradually, she started recovering through a very painful experience. It was a nerve-testing time for her as well as for the entire family. The researcher's 
younger sister and the researcher stayed with their mother (termed as the participant henceforth) in the hospital during the whole period and this resulted in drastic changes in our lifestyles. The participant's doctor guided us about how to interact with our mother and modify our responses. Eventually, these changes became an indispensible feature of our personalities. The participant became infantilized, and we transformed as parentified. The most noticeable change occurred in our communication patterns. The researcher had always loved her mother and had been deeply concerned about her health, but she had never been emotionally expressive. She realized that her beloved mother needed explicit display of love and continuous support from her near and dear ones. This meant emotional expressivity along with physical assistance. The result was a transition in the researcher's communication patterns. She had been noticing changes in her communicating style along with the research participant's. Some of the techniques in her own speech were not known to her as she was not conscious about the strategies she had been employing. Later, she wanted to explore them systematically. Her academic background equipped her with the techniques desired for exploring the special features of her parentified communicating style.

\section{REVIEW OF LITERATURE}

Mental health of a person and emotional expressivity are directly related to each other. It is an established fact in health psychology, social psychology, personality psychology and psychopathology (Akin, Satici, \& Kayis, 2012). Gross and John (1997) suggest a model of emotional process in which the environmental changes trigger and shape emotional responses.

Emotional expressivity positively affects general health. Foucault talks about the natural locus of life which he defines as gentle, pure love and expressivity. A genuine concern for the ill and care (in the caregiver) are synonymous with a natural desire for cure (in the aphasic) and if they coexist, the healing process can be activated (Foucault, 2003). Emotional attachment helps in arousing positive and healthy emotions in the aphasic (Bowlby, 1982), but if the same is overlooked about one's own self, the result is catastrophe. An emotionally intelligent caregiver possesses two important qualities: responsivity and expressivity. Although men and women both can adopt the role of a caregiver for an aphasic, females are potentially better caregivers as they are also commonly known as emotional beings (Oatley, 2004). This emotional intelligence equips them with enough empathy desirable for helping an aphasic in recovering language. More emotional expressivity results in establishing better relationships (Burgin et. al, 2012) but women in the eastern society are denied emotional expressivity. Folk linguistically speaking, it is a taboo, unlike a ladylike attitude to be emotionally expressive. Paradoxically, when it comes to taking care of the dear family members suffering from serious physical and psychological ailments, it is believed to be the females' job to support the sufferer in both ways. It can be anyone like a daughter, a sister, a mother etc.

A person suffering from a long-term ailment depends a lot on his/her caregiver to recover. Stroke and aphasia are among these ailments as they take a long course of time for recovery. The sufferer's future almost totally depends on having a full-time caregiver. Naturally, more demands are on the shoulders of the caregiver. So, s/he must make more adjustments and emotional sacrifices. It is taken for granted to adjust themselves according to the changed situation. Emotional expressivity is one such thing that is demanded from them. Not ready for such a drastic change in their disposition and behavior, females are endangered to suffer from serious consequences such as denial, low selfesteem, apathy, frigidity and eventually, poor relationships.

Every child is attached to its mother. This attachment behavior never vanishes; it remains with every individual throughout life. It may hibernate during maturity as it is not expressed explicitly, yet it never vanishes. If an aphasic has not been emotionally satisfied during childhood, his/her love needs persist and regression occurs. Stroke can cause these hibernated love needs to become visible as a continuation of the regressive process. The caregiver is the same as the real mother is for the infant and so does the mothering for the aphasic (Bowlby, 1973). In the process of doing mothering for the aphasic, the caregiver in most cases starts sacrificing his/her own emotions just like the real mother does for her child.

Initially, every aphasic becomes infantilized (Epstein, n. d.) as s/he must totally depend on the caregiver. This leads to orienting him/her to be more demanding than a 'normal' person in terms of having a recurrent emotional assurance and explicit emotional display by his/her caregiver. Thus, the result can be a regressive, parasitic behavior on the part of the aphasic and a compromising, 
submissive behavior, or low self-esteem on the part of the caregiver. The caregiver or the parentified child must negate the fact that $\mathrm{s} / \mathrm{he}$ is the daughter/son, and the infantilized aphasic is in fact the mother/ father. S/he takes refuge by dissociating herself/himself from reality as it helps in coping with stress during such a traumatic event. The dissociated caregiver disconnects himself/herself from the world to avoid suggestions or criticism about his/her behavior towards the aphasic as they might find it quite weird. Depending on personal experiences, every caregiver is unique.

The caregivers are generally oriented by the physicians to become more flexible and tolerant than before to handle the aphasic. Their emotional concern for the sufferer generates empathetic stress. It gets activated when we observe others' stress. The human brain controls all types of physical and mental activities. The whole process is done with the help of over one hundred billion neurons (Kalat, 2004) which organize themselves into clusters during the maturation process. Each cluster specializes in performing one particular function. There is a specialized group of neurons in the brain called the mirror cells that start replicating that stress (Hoiser, 2016). This results in what the psychologists term as empathy. It is a mental as well as a physical process and hence the caregiver of the aphasic is experiencing two types of severe stress: the empathetic stress and his/her own stress to assist the sufferer. This puts the emotions in a high arousal position. Moreover, empathy means 'to feel like someone else'. This means that a person feeling like someone else overlooks his/her own emotions. According to Paul Ekman, an emotion lasts only a few seconds (as cited in Goleman, 2006) yet a sustained emotion, especially the one that raises blood pressure causes high level of chemical secretion in the blood can be fatal. The caregiver who is providing full-time emotional assistance and physical support to the aphasic is actually at a high risk of losing emotional balance by suppressing his/her own emotional needs.

Emotions have biological manifestation in the body as the brain generates certain chemicals or electric waves while giving emotional orders to the body. A negative emotion must result in releasing a negative or harmful chemical and a continuous experience of a negative emotion must add to negativity causing physical ailments as well. They also cause positive emotions to wither away. This leads to perversion in emotional dealings and bad relationships.

A consciousness about the aphasic's emotional needs and empathy may also entice one towards adjusting and mending his/her emotional dealings. This helps in regulating his/her emotional life.

\section{THEORETICAL FRAMEWORK}

Norbert Wiener's concept of cybernetic has been incorporated as the theoretical lens through which the phenomenon of parentification has been scrutinized. Cybernetics refers to the self-regulating mechanisms (Wiener, 1985). The researcher has modified the idea of cybernetics and has used it to mean emotional self-regulating mechanisms that the parentified caregiver develops and through emotional navigation it becomes automated. Parentification may be a time irreversible process, but it is not necessarily emotional entropy. It can be rewarding and enlightening. It just adds another value to the overall human emotional analog! Emotional expressivity helps regulate the emotional life of the parentified figure. The conventional concept of parentification presents the sufferer as the parasite, the sole advantage taker who benefits at the expense of the host or the caregiver. This study implicates that symbiotic relationship can be cultivated between the two if betterment of both is desired. Being the stronger partner in the relationship, it is the caregiver's job to devise a self-regulating emotional mechanism.

Occasionally breaking free can energize and revitalize the caregiver. Self-replication can be accelerated within the anabolic process by getting involved into activities of your choice. It generates positive feelings and hence, is helpful for becoming optimistic. It has a healing effect over the emotional burnout. Continuous, chronic stress causes emotional and physical burnout that is catabolic. Parentification is a subjective experience, an utterly ontogenetic learning. Through self-regulation and emotions management, the parentified figure can even become emotionally enlightened and emotionally intelligent.

\section{MATERIALS AND METHODS}

The data collection methods included diary, audio recordings and discussions with the doctor of her mother (who became infantilized). All the data were recorded over a period of one year. The 
researcher was interested in exploring what happened to her own speech while communicating with the research participant. She also wanted to investigate whether her speech underwent changes or not. If yes, what were those changes and which factors determined these changes. This study explores the emotional contours of communication. That is why only the paralinguistic features of the researcher's communication have been focused and analyzed.

The aphasic with the left brain (or the left hemisphere) damaged has his/her emotional communication intact as the right brain (or the right hemisphere) is intact. Goleman (2006) suggests that the rational mind (left hemisphere) communicates through linguistic or verbal methods and the emotional mind (right hemisphere) communicates through non-linguistic ways such as bodily gestures, facial expressions, etc. The aphasics with the left hemisphere damaged have a weaker logical side and a stronger emotional side (Lorch, Borod \& Koff, 1998). His/her communication is more emotional and nonlinguistic than rational and linguistic. The research participant in this study had a stroke that affected her left hemisphere which means that her logical/linguistic side of communication was damaged whereas her right hemisphere was intact. This means that her emotional/non-linguistic side of communication was intact. Therefore, the researcher has focused on the emotional contours of communication or the paralinguistic features.

\section{Methods of Data Analysis}

The paralinguistic analyses included exploration of the intonation, stress, and tempo. The analysis of intonation generally involves a distinction between a rising and a falling tone (Crystal, 1994). Thus, the tonal analysis in this study is based on the use of rising and falling tone to check whether the researcher's speech was monotonous, or she could experiment with different tones. Stress has been studied by considering the words in her speech uttered with more prominence than the surrounding words and tempo has been measured through the spontaneity of response and the number and length of pauses during her speech.

\section{Research Questions}

1. What are the features of the speech of a parentified figure?

2. How can parentification be made a positive, fruitful experience?

\section{Methodology}

The data were collected for one year, that is, from June 2011to May 2012. They were either audio recorded or noted down as diary entries. They included the everyday, mundane conversations between the research participant and the researcher as this study is all about uncovering the communicative patterns of the research participant's speech. Hence, only the researcher's speech features have been analyzed. For data transcription, Gail Jefferson's (1983) transcription conventions and symbols have been used (see Appendix C). The transcriptions have been done in Roman. The researcher's and the participant's main language of communication was Urdu, so the Urdu sounds were converted into Roman symbols (see Appendix D). English translations of the recorded conversations have been provided in parentheses along with the transcriptions. For the sake of convenience in typing, some abbreviations have been devised. Thus, $\mathrm{P}$ stands for Participant, $\mathrm{R}$ stands for Researcher, AD stands for Audio Recordings, DE stands for Diary Entries and DD stands for Discussion with the Doctor. The researcher had a total of four discussions with the doctor of the research participant over a period of one year. DDI represents the first discussion, DDII represents the second discussion, DDIII stands for the third discussion and DDIV stands for the fourth discussion with the doctor. The excerpts of the data relevant to this study have been presented in the data section. The full versions of the audio recordings have also been provided along with the write-up. For the reader's convenience, the data have been arranged in the form of a dialogue. The date and the source of data collection are mentioned.

\section{Data Presentation}

$\mathrm{P}$ and $\mathrm{R}$ are sitting in P's room and chatting. There are family albums in front of them.

Lines 1- 5 from AR on 4.7. 2011. For the same Lines also refer to DD II on 25. 9. 2011 on the CD.

$1 \mathrm{R}: \uparrow$ keyaa par reyee thin 


\section{Emotional Enlightenment: An Optimistic Approach Towards Parentification}

(what were you reciting?)

2 P: wo parti hai BISMilaahirahmaani ${ }^{\circ}{ }^{\circ}$ raheem ${ }^{\circ \circ}$

(she recites in the name of God, Most Merciful, Most Beneficent)

$3 \mathrm{R}$ : achaa is ko keyaa bataatey hain bismilaa $\uparrow \mathrm{ko}$

(ok what do they call Bismila?)

4 P: ba bas koee par neyee sakți bas BISMILAAHIRAHMAANIRAHEEM (1.0) yeyhee parti

5 raiti hoon

(I cannot recite anything else so I keep on reciting only Bismilahirehmaniraheem)

$\mathrm{R}$ asks $\mathrm{P}$ the dish she loved most. She wants $\mathrm{P}$ to tell her about its recipe as well.

\section{Lines 6-15 from AR on 21.6. 2011}

$6 \mathrm{R}$ : bataaeyn naan bhindiaan kaisey banaatey $\uparrow$ hain

(tell me how to cook okras)

7 P: $\downarrow$ bhindieyn bhi pailey (3.0) yey ey pakaati hain key dhoaa key $\uparrow$ naan yey: : (2.0)

8 ey parparaati (.) yey kaitey hain yey ( )

9 R: $\uparrow$ peyaaz

(first wash okras then put)

(onions)

$10 \mathrm{P}$ : $\uparrow$ haan (.) naan neyeen ba baad meyn (.) pailey yey $\downarrow$ rakhwaati ain (1.0) PAANI ni ni

11 yey keyaa hotaa $\uparrow$ hai (1.0) paani yey keyaa hotaa $\uparrow$ hai (yes, no put it later first add water no not water what is it called?)

12 R: PINDIAAN (okras)

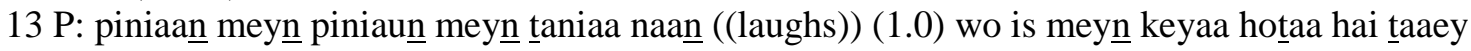

14 taa keyaa otaa ai (first add coriander in okras no it's?)

15 R: mircheyn

(chilies)

$\mathrm{P}$ also talks about the sweet dishes she loved to cook and starts discussing about the approaching religious festival.

\section{Lines 16-19 from AR on 19.7.2011}

$16 \mathrm{R}$ : to aaj gudee kuch pakaaey gi shabaraat pey

(will Guddee cook something today it's Shab-e Baraat today)

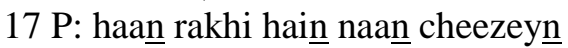

$$
\text { ( yes she has kept something) }
$$

$18 \mathrm{R}: \uparrow$ keyaa pakaaey gi GUDEE

19 P: ey ALWAA

$$
\text { ( what will Guddee cook?) }
$$

(halwa)

$\mathrm{P}$ and $\mathrm{R}$ are practicing reading and speaking. $\mathrm{R}$ writes some words on the paper and asks $\mathrm{P}$ to read them. All words written are related with the topics that $\mathrm{P}$ is attached with.

Lines 20-24 from AR on 20.8.2011.

20 R: achaa ab main yey LIKHOON gi aap ney parnaa ai (.) aap pareyn main ney keyaa likhaa

21 ai yey deykheyn (1.0) 个main ney likhaa:: (3.0) keyaa 个likhaa: (ok now I'll write and you'll read it read what I have written look here see what have I

written?)

$22(4.0)$

23 P: $\downarrow$ alaa

(God)

$24 \mathrm{R}: \uparrow$ alaa:: $\uparrow$ shaabaash or yey:

(God good and what's this?)

\section{Lines 25-28 from AR on 21.8.2011}

25 R: momo yey pareyn zaraa main ney keyaa likhaa ai (2.0) $\uparrow$ yey:: (1.0) yey keyaa $\uparrow$ likhaa (mama please read it what did I write here?)

$26(2.0)$ 
27 P: $\downarrow$ alaa

$$
(G o d)
$$

$(G o d)$

$\mathrm{P}$ turns on the TV as $\mathrm{P}$ wants to watch some program. There's a documentary about India.

\section{Lines 29-31 from AR on 6.12.2011}

29 R: ab yey keyaa ai (.) yey deykheyn:

(now what's this look at this)

30 P: yey BUDEY ain naan ((laughs))

(these are old people)

31 R: neyee neyee yey yey yey::

(no no this this this)

$\mathrm{R}$ turns on the TV again. This time some wild dogs appear on the screen. P points at the wild dogs in a low voice as R's sister Guddee is sleeping.

Line 32 documented as a DE on 19.10.2011

$32 \mathrm{P}:{ }^{\circ}$ papraa ab yey is key baut bachey ain naan yey jangli kutey ain $\underline{n}^{\circ \circ}$ (now it has many puppies aren't they? these are wild dogs)

\section{Lines 33 \& 34 from AR on 19.10.2011}

33 P: eyk kutaa otaa ai (.) goondaa (.) goondaa otaa ai (there's a dog which is deaf)

34 R: GOONGAA hotaa $\uparrow$ ai (it's deaf)

\section{Lines 35-38 from AR on 8.10.2011}

35 P: oon (.) $\downarrow$ a keyaa otaa ai (2.0) chitaa ey chitaa darmeyaanaa saa (it's white white no medium one)

36 R: achaa ofwaait (1.0) $\downarrow$ theek ai (2.0) achaa ab kahaani partey ain chaleyn ab bataaeyn mujey

37 yey keyaa likhaa ai (4.0) $\downarrow$ jaadoo kaa kaaleen

38 P: $\downarrow$ achaa (ok off-white right now let's read a story you tell me what is this written? magical carpet) $(o k)$

$\mathrm{R}$ asks $\mathrm{P}$ about the repairs in the house that need to be done before the party. She asks about the carpenter.

\section{Lines 39-43 from AR on 18.11.2011}

39 R: ACHAA $\downarrow$ bilkul $\uparrow$ kaa:m kab sey shuru karna ai us $\uparrow$ ney (ok that's right so when will he start the work?)

40 P: yey neyee pataa waisey aaeyaa thaa saari cheezeyn udar ley:: key $\uparrow \underline{\text { do: }: \text { aadmi they naan }}$

(I have no idea but he came with everything there were two men)

$\mathrm{R}$ asks about P's grandson whom she loves most. He has just been operated upon.

$41 \mathrm{R}$ : biloo theek $\uparrow \mathrm{ai}$ ab

(is Billoo fine now?)

42 P: biloo mashala theek ai (.) haañ:: zaraa phir to neye saktaa waisey theek ai daktar saab

43 kaitey ain zeyaadaa abi phirnaa naan zeyaadaa ((rooster crows)) ain: daktar $\downarrow_{\text {saa }}$

( Billoo is mashala fine yes though he can't walk but otherwise he's fine the doctor says so)

$\mathrm{P}$ tells $\mathrm{R}$ that a relative also came in $\mathrm{R}$ 's absence.

\section{Lines 44-49 from AR on 15.4. 2012}

$44 \mathrm{R}$ : aap ki $\uparrow$ keyaa lagti ai (what relation does she have with you?)

45 P: meyri:: yey naan kon ai wo: (4.0) $\downarrow$ ka kazan ai naan wo

$46 \mathrm{R}: \uparrow h a a n:::$ (my she's my cousin isn't she?)

$$
\text { (yes) }
$$

47 P: wo to wo: cho:ti:: ai naan wo ( (isn't she young? she her my)

) wo naan (1.0) us ki:: (2.0) $\downarrow$ meyri:

$48 \mathrm{R}$ : khaalaa ki larki ai 


\section{Emotional Enlightenment: An Optimistic Approach Towards Parentification}

49 P: $\uparrow$ haan:

(maternal aunt's daughter)

(yes)

$\mathrm{P}$ takes out her rosary and starts doing recital on it.

Lines 50-64 from AR on 3.3.2012

$50 \mathrm{R}:$ keyaa par reyee $\uparrow$ ain

(what are you reciting?)

51 P: main (.) bismilaahirahmaaniRAHEEM (.) yeyee $\downarrow$ par sakti oon

(it's Bismilahirahmaniraheem as I can recite only this much)

52 R: or $\uparrow$ neyee par saktin $(2.0)$ or ( ) aap $\uparrow$ inshaalaa bi to $\uparrow$ par sakti $\uparrow$ ain

(and can't you recite anything else? you can rectie Inshala as well)

53 P: bas woee ai bismilaa ee ai ( ) BISMILAAHIRAHMAANIRAHEEM

(it's only Bismila Bismilahirahmaniraheem)

$P$ tells $R$ that her paternal grandfather grew up in India.

For Lines 54-64 also refer to DD IV on 9.5.2012 on the CD.

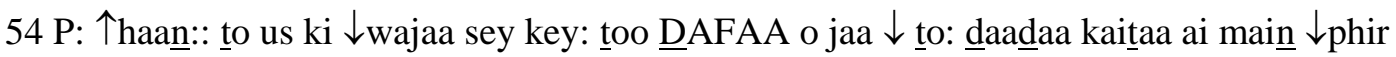
55 UDAR jaa raa thaa phir too thorey to ( ) din baad us ko: too:: laahol chalaa jaa:: phir 56 udar: laahol jaaey phir kaiey key idar ( ) ((plane passes)) (4.0) IDAR chalaa jaa baut 57 TANG kartey they usey baut TANG kartey they (.) phir kaitey ain itnaa bimaa:r o geyaa 58 naan tumaaraa daadaa daa:daa bimaar o geyaa thaa naan $\uparrow$ bachaa un kaa (1.0) kaitey ain 59 theek o geyaa ${ }^{\circ}$ phir theek o geyaa ${ }^{\circ \circ}$ phir bachaa theek o geyaa bachaa theek o geyaa 60 ( )bas (1.0) bas theek inshaalaa theek ai wo thee::k o geyaa ai $\downarrow$ inshaalaa ( ) main 61 ney bas alaa taalaa sey karwaa diaa yaa alaa taalaa bachaa theek o ja:ey $\downarrow$ theek THEE:K ee o 62 geyaa ${ }^{\circ \circ}$ theek o geyaa achaa theek ai ${ }^{\circ \circ}$ kaitaa ai alaa taalaa ( ) sey kaitaa ai naan key 63 agar main alaa taalaa sey alaa taalaa sey yey: kiaa yaa: alaa taalaa meyraa bachaa thee:k o 64 jaaey yaa alaa meyraa bachaa ( )o jaaey baut TANG paraa

(yes that's why he said you get lost so your paternal grandfather said he went there then after some days he would say go to Lahore and he would go to Lahore then he would say go there they used to annoy him a lot so he says he got ill your paternal grandfather got ill his son got well his son got well Inshala he's fine I prayed to God to bless him with health he got well he says he prayed to God to bless his son with health he got irritated)

\section{RESULTS AND DISCUSSION}

Intonation. Table I displays the tonal features of the R's speech.

The rising tone in R's speech worked the same as question tags do in the 'normal' speech, that is to add emphasis (Crystal, 2006). The $\mathrm{R}$ replaced a linguistic feature (question tag) with a paralinguistic feature (rising intonation) as she was employing the paralinguistic channel of communication. The use of a rising tone can also be compared with strong forms of words in the normal speech as they are used to drop hints about the intensity of expression (Jones, 1976).

In normal speech, a whisper-like tone indicates secrecy, or a desire to hide something (Crystal, 2006). The R's switching to this tone can also be because she wanted to hide the P's linguistic inability.

Stress. Table II displays the words which were stressed in the R's speech. Generally, stress carries emotional contours of the normal speech (Roach, 1983). The R stressed the content words because she thought them to contain the communicative intent and said them accurately and she stressed only the most important word only as she wanted to make it easily intelligible to the interlocutor (Crystal, 2006).

Tempo. The tempo of the R's speech has been studied by considering her response time to the P. The R's responses were always spontaneous and very quick. The tempo of her speech was also tested by considering the pauses taken by her within her speech and also by focusing on the duration of each pause. The overall tempo of the R's speech is mentioned in Table III.

The speed of speaking reflects the intentions of the speaker (Roach, 1983). Crystal (2006) explains that pauses within speech are a way of emphasizing words' identities. They also serve as the 
internal simplicity measure (Chomsky's phrase as cited in McGilvray, 2009) for the R as it exhibits her preference for the simplest possible language for becoming understood by the P. The R's sensitivity for the emotional, paralinguistic features of communication was aiding her in communication with the P. It also put "lower cognitive demands" in terms of communication (a phrase used in Everaert, Lentz, Mulder, Nilsen \& Zondervan, 2010) on the P. Thus, the R's mode of communication heavily depended on the field (context) of her language use assumed an automatic tenor (connection with her interlocutor) (Halliday's terms, 2004). The R's communication was mainly based on the use of content words and can be called monosemantic (Halliday, 1994) as it lacked the duality of meanings. Thus, the R's speech was clear and conveyed exactly what it aimed at.

The study displays that the R's speech was gradually becoming automatized (Vygotsky's term as cited in Veer \& Valsiner, 1994), involving nominal conscious effort. The analyses of the paralinguistic features of the R's speech display that she was orienting and adjusting her speech patterns according to the needs of the P. The analyses also indicate that the R's speech was centered around one idea: to maximize ease and comfort level of the P. And this means a continuous empathetic stress.

To empathize means to feel like someone else and if you feel like someone else you neglect your own self. It means apathy towards your own emotions while experiencing empathetic stress. A continuous practice like this leads to self negation, self denial and deprivation leading to serious emotional hazards, low self esteem and burnout etc. Stress regulation can help deal with such consequences. It can be distraction in the form of involving into activities that you love doing as break free (for brief durations). Stress management can be taken as a three-stage activity: Empathetic StressStress Regulation-Stress management. Stress management can be compared with Daniel Goleman's idea of emotional management. Stress is experienced as a change in physical and emotional state. 'Know thyself', 'Know thy emotions' is the only remedy for dealing with emotional burnout out emotional regulation and emotions management. The researcher suggests that stress management eventually leads to emotions management.

Emotional adaptation means molding the most primary emotions into an impetus for communication. It involves a retraining and transition of the primary emotions (Oatley, 2004).

The caregiver's emotional intelligence aids him/her in attaining self-regulation. Distraction from bleak situations helps in releasing tension (Dolf Zillman as cited in Goleman, 2006) and focusing on what generates optimism, can serve as a self-replication technique.

\section{CONCLUSION}

The emotional silhouette was not clear to the $\mathrm{R}$ before the experience. It proved to be a rewarding experience as it helped her in outlining and eventually managing her relationships in a better way. It engendered confidence by equipping her with words that were emotionally charged. The researcher has always been extremely emotional about her family and her relationship with the family, but she was unexpressive. The tables below display that her speech was rich in paralinguistic features (intonation, stress, tempo) making it emotionally charged:

Vygotsky views intellectual development as a shift in the development process that is from phylogenetic development to ontogenetic development. He also claims that the neuron specialty is a matter of experience. A neuron can be trained to work in many ways as it is flexible. Thus, the innate reflexes which are fixed, become flexible or plastic through experience and can perform multiple functions. This plasticity in reflexes enables a normal human to learn unlimited motor skills (Veer \& Valsiner, 1994). Emotional expressivity is also a motor skill and hence can be learned by anyone. This is what Vygotsky discusses in his theory of reflexology (Veer \& Valsiner, 1994).

Table No. 1: Intonation Pattern

\begin{tabular}{lll}
\hline Line \# & $\begin{array}{l}\text { Rising Tone } \\
\text { (Frequency) }\end{array}$ & $\begin{array}{l}\text { Falling Tone } \\
\text { (Frequency) }\end{array}$ \\
\hline 1 & 1 & - \\
3 & 1 & - \\
6 & 1 & - \\
9 & 1 & - \\
18 & 1 & - \\
\hline
\end{tabular}




\begin{tabular}{lll}
\hline 21 & 2 & - \\
24 & 2 & - \\
25 & 2 & - \\
28 & 1 & - \\
34 & 1 & - \\
36 & - & 1 \\
37 & - & 1 \\
39 & 2 & 1 \\
41 & 1 & - \\
44 & 1 & - \\
46 & 1 & - \\
50 & 1 & - \\
52 & 4 & - \\
\hline
\end{tabular}

Table No. 2 Stress Pattern

\begin{tabular}{lll}
\hline Line \# & Stressed Word (s) & \# of Stressed Words \\
\hline 12 & PINDIAAN & 1 \\
18 & GUDEE & 1 \\
20 & LIKHOON & 1 \\
34 & GOONGAA & 1 \\
39 & ACHAA & 1 \\
\hline
\end{tabular}

Table No. 3: Tempo

\begin{tabular}{lll}
\hline Line \# & No. of Pauses & Duration of Pause(s) \\
\hline 21 & Two & $1 \mathrm{sec} ., 3 \mathrm{sec}$. \\
25 & Two & $2 \mathrm{sec} ., 1 \mathrm{sec}$. \\
36 & Two & $1 \mathrm{sec} ., 2 \mathrm{sec}$. \\
37 & One & $4 \mathrm{sec}$. \\
52 & One & $2 \mathrm{sec}$. \\
\hline
\end{tabular}

The data analyses above exhibit how the speaking style of the researcher underwent change after becoming parentified. It can be seen that her speech had a dominant use of a rising tone, a prominent stress on the most important words in each sentence and slow pace of speaking. All these features prove her speech to be different from 'normal' speech. She involved these features in her speech to facilitate the $\mathrm{P}$ during the communication process.

Parentification is an extremely unique experience. Normally, nobody is ready for it or gets trained for that. It is a kind of paradigm shift for the family make-up, a time to start afresh. The researcher realized that her role in the family changed overnight. Initially, it was an exasperating, terrifying feeling but eventually when she started focusing on her mother's plight, insecurity, and dependence, she realized how petty her fears were and how great the task ahead was! She had to muster up her courage. She decided to struggle and fight for her mother. This conscious role realization helped her plan future actions and eventually, she felt relaxed as her mother started feeling secure and relaxed.

Goleman talked about self-awareness, self-motivation, and self-regulation and when it comes to taking on the role of a parentified figure these ideas become very crucial. In fact, before taking on the job of a caregiver or a parent-like figure, one must convince himself/herself about the serious undertaking. Any delay and the result are a two-way disaster, as it will affect not only the aphasic a but also the caregiver who is about to become parentified. It must be emphasized that the caregiver must know this phenomenon consciously that his/her future emotional life is going to change forever.

Parentification is a lifestyle that has to be adopted, it can be a parasitic relationship as well as a symbiotic one. The traditional explanation portrays it as parasitic as generally the parentified child overlooks his/her own emotions. This study implicates that emotional adaptivity gained through emotional intelligence can aid in developing a symbiotic relationship which eventually proves parentification to be an enlightening, fruitful experience that can help in maintaining emotional balance in all other relationships and hence aids in becoming better human beings. 


\section{REFERENCES}

Akin, A., Satici, S. A. \& Kayis, A. R. (2012). Emotional expressivity and submissive behavior. Journal of Education and Instructional Studies in the World. 2(1) www.wjeis.org/FileUpload/ds217232/File/01x.akin.pdf

Bowlby, J. (1973). Attachment and loss : separation, anxiety and anger (Vol. II). The USA, Library of Congress Catalog Card No. 70-78464. -.(1982). Attachment and loss: attachment (Vol. I, 2nd ed.). New York, Basic Books.

Burgin, C. J., Brown, L. H., Royal, A., Silvia, P. J., Barrantes-Vidal, N., \& Kwapil, T. R. (August 01, 2012). Being with others and feeling happy: Emotional expressivity in everyday life. $\begin{array}{llll}\text { Personality and Individual } \quad \text { Differences, } & \text { 53(3), }\end{array}$ https://libres.uncg.edu/ir/uncg/f/T_Kwapil_Being_2012.pdf

Crystal, D. (1994). The Cambridge encyclopedia of language. The USA, Cambridge University Press. . (2006). The Cambridge encyclopedia of the English language $\left(2^{\text {nd }}\right.$ ed.) The UK, Cambridge University Press.

Epstein, R. (n. d.) Do people treat you like a child? http://howinfantilizedareyou.com/

Everaert, M., Lentz, T., Mulder, H. D., Nilsen, O. \& Zondervan, A. (Eds.) (2010). The linguistic Enterprise: From knowledge of language to knowledge of linguistics. Amsterdam/Philadelphia, John Benjamin Publishing Company.

Foucault, M. (2003). The birth of the clinic: an archaeology of the medical perception (A.R. Sheridan Trans.). Britain, Taylor \& Francis e-Library.

Goleman, D. (2006). Emotional intelligence. The USA, Bantam Dell.

Gross, J. J., \& John, O. P. (1997). Revealing feelings: facets of emotional expressivity in self-reports, peer ratings and behavior. National Center for Biotechnology Information, US, National Library of Medicine https://www.ncbi.nlm.nih.gov/pubmed/9107009

Halliday, M. A., \& Matthiessen, C. M. (2004). Halliday's introduction to functional grammar (3 ${ }^{\text {rd }}$ ed.). Routledge, Taylor \& Francis Group.

Halliday, M. A. (1994). An introduction to functional grammar ( $2^{\text {nd }}$ ed.). China, Edward Arnold (Publishers) Ltd.

Hoiser, D. (2016). Empathetic stress and its effects on babies' psychological development. child abuse, trauma and recovery. http://childhoodtraumarecovery.com/2016/04/10/empatheticstress-effects-babies-psychological-development/

Jones, D. (1976). An outline of English phonetics $\left(9^{\text {th }}\right.$ ed.). Great Britain, Cambridge University Press.

Kalat, J. W. (2004). Biological psychology ( $8^{\text {th }}$ ed.). Canada, Wadsworth.

Lorch, M. P., Borod, J. C., \& Koff, E. (1998). The role of emotions in the linguistic and pragmatic aspects of aphasic performance. Journal of Neurolinguistics 2 (1) \& 2 (2), The USA, Elsevier Ltd. http://www.sciencedirect.com/science/article/pii/50911604498000086

McGilvray, J. (Ed.) (2009). Cartesian linguistics: a chapter in the history of rationalist thought. $\left(3^{\text {rd }}\right.$ ed.). The UK, Cambridge University Press.

Oatley, K. (2004). Emotions: a brief history. The USA, Blackwell Publishing Ltd.

Veer, R. V., \& Valsiner, J. (Eds.) (1994). The Vygotsky reader. Leiden University, Blackwell. http://www.marxists.org/archive/vygotsky/works/reader/index.htm

Vygotsky, L. (1962). Thinking and speaking (E. Hanfman \& G. Vakar Trans.). The MIT Press. http://www.marxists.org/archive/vygotsky/works/comment/vygotsk1.htm

(2010). An interdisciplinary theory of activity (A. Blunden Trans.). The Netherlands, Koninklijk Brill NV, Leiden.

WebMD. (n.d). Mom's guide to family health: new year food and fitness http://www.webmd.com/parenting/family-health-2/slideshow energy-foods

Wiener, N. (1985). Cybernetics or control and communication in the animal and the machine ( $2^{\text {nd }}$ ed.). The M. I. T. Press, Cambridge, Massachusetts, The USA. 


\section{Appendix-C}

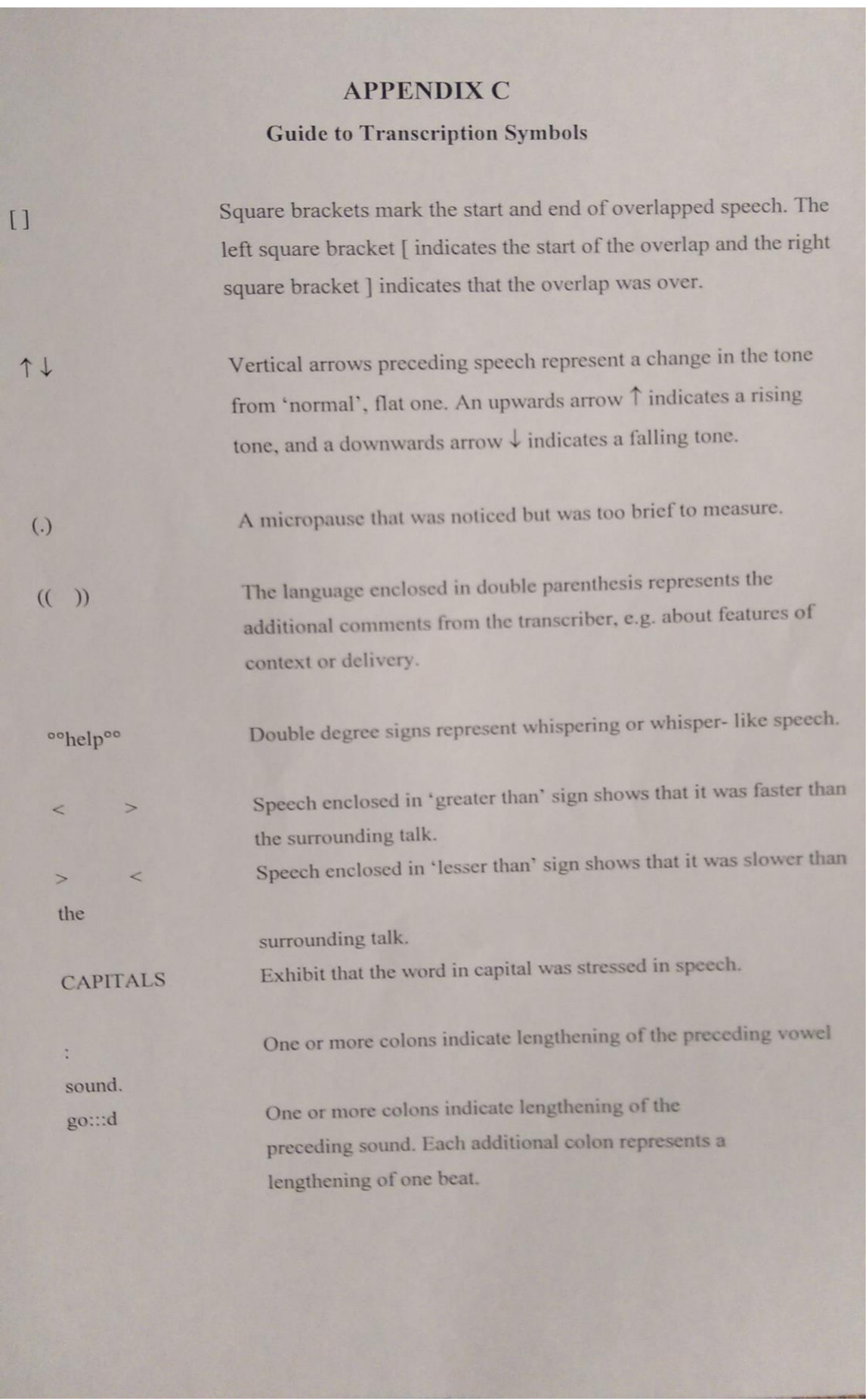




\section{Qayyum, Qayyum, \& Qayyum}

$$
\text { Numerals in parentheses mark pause in seconds. }
$$
A stretch of talk that was unintelligible.

The space between the parentheses indicates the length of the unintelligible talk.

Adapted from Gail Jefferson's Transcription Symbols as cited in Have (2004), pp. 183 \& 184 


\section{Appendix-D}

\section{APPENDIX D}

Key to Roman Symbols of Urdu Sounds (along with examples)

Note: Each Urdu monophthong or consonant sound in the chart below comes in the initial position of the word(s) in front of it except in the words $+2,31 \%$, and the sound comes in the medial position.

\section{Monophthongs \& Consonants}

\begin{tabular}{|c|c|c|c|}
\hline Serial \# & Roman Symbol & Specimen Word(s) & Urdu Sound \\
\hline 1. & a & ان · مبرل & $\varepsilon \cdot i$ \\
\hline 2. & $\mathrm{i}$ & U! & $!$ \\
\hline 3. & $\mathrm{u}$ & أ & i \\
\hline 4. & C & $4=$ & $<1$ \\
\hline 5. & 0 & اנر & ו \\
\hline 6. & b & رن & بب \\
\hline 7. & $\mathrm{p}$ & بي & ? \\
\hline 8. & $\underline{1}$ & 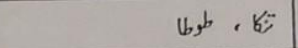 & $b \cdot ت$ \\
\hline 9. & $t$ & باب & 2 \\
\hline 10. & $\mathrm{~s}$ & ثر. انب . مان & $s \cdot v \cdot 3$ \\
\hline 31. & $\mathrm{j}$ & - & ¿ \\
\hline 12. & ch & $l^{2} z$ & ت \\
\hline 13. & h & 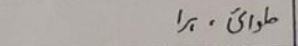 & $\cdot 2$ \\
\hline 14. & $\underline{\mathrm{kh}}$ & 6. & $\dot{z}$ \\
\hline 15. & $\underline{\mathrm{d}}$ & ניט & , \\
\hline 16. & d & زُول & ; \\
\hline 17. & $\mathrm{z}$ & زرا · زياره •غرب بز & $\dot{b} \cdot \dot{j} \cdot j \cdot j$ \\
\hline 18. & $r$ & v & , \\
\hline 19. & $\underline{r}$ & 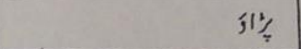 & j \\
\hline 20. & y & زاله . يl, & $<v$ \\
\hline 21. & sh & ث. & $\dot{\vec{U}}$ \\
\hline
\end{tabular}




\begin{tabular}{|c|c|c|c|}
\hline 22. & gh & نايَب & $\dot{i}$ \\
\hline 23. & $\mathrm{f}$ & نالوه & ن \\
\hline 24. & $q$ & تاعده & ت \\
\hline 25. & k & كوب & $\checkmark$ \\
\hline 26. & $\mathrm{~g}$ & كرم & 3 \\
\hline 27. & 1 & لو & J \\
\hline 28. & $\mathrm{~m}$ & 屹 & r \\
\hline 29. & $\mathrm{n}$ & i & ن \\
\hline 30. & w & وعره & , \\
\hline 31. & $\underline{\mathrm{n}}$ & זكهم & $u$ \\
\hline
\end{tabular}

Note: Each Urdu aspirated consonant sound in the chart below comes at the initial position of the word(s) in front of it except in the word lom where the sound comes at the medial position.

\section{Aspirated Consonants}

\begin{tabular}{|c|c|c|c|}
\hline Serial \# & Roman Symbol & Specimen Word(s) & Urdu Sound \\
\hline 1. & bh & úlọ' & s. \\
\hline 2. & $\mathrm{ph}$ & 禹 & $\phi$ \\
\hline 3. & $\underline{\text { th }}$ & $\ddot{\gamma}$ & $\ddot{\infty}$ \\
\hline 4. & th & ( & $\omega^{3}$ \\
\hline 5. & jh & ?جائو, & क? \\
\hline 6. & $\underline{\mathrm{ch}}$ & جعمالي & $\stackrel{3}{3}$ \\
\hline 7. & $\underline{\mathrm{dh}}$ & r & $\infty$ \\
\hline 8. & dh & 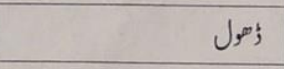 & ; \\
\hline 9. & $\underline{\mathrm{rh}}$ & Lom? & f \\
\hline 10. & $\mathrm{kh}$ & 165 & $\delta$ \\
\hline 11. & gh & 8 & $\xi$ \\
\hline 12. & $\mathrm{mh}$ & $\not 6$ & $\infty$ \\
\hline
\end{tabular}


Note: Each Urdu long vowel sound or diphthong in the chart below comes at the initial position of the word in front of it.

\section{Long Vowels \& Diphthongs}

\begin{tabular}{|c|c|c|c|}
\hline Serial \# & Roman Symbol & Specimen Word(s) & Urdu Sound \\
\hline 1. & aa & آز & $i$ \\
\hline 2. & oo & أز口 & أُ \\
\hline 3. & ee & ! يi! & U! \\
\hline 4. & ey & آي - ا & $<1$ \\
\hline 5. & ai & أي & Li \\
\hline
\end{tabular}

Note: Each Urdu nasalized vowel sound in the chart below comes at the final position of the word in front of it.

\section{Nasalized Vowels}

\begin{tabular}{|c|c|c|c|}
\hline Serial \# & Roman Symbol & Specimen Word(s) & Urdu Sound \\
\hline 1. & on & لركيول & اون \\
\hline 2. & oon & אצ:ט & أُول \\
\hline 3. & eyn & كري & إي \\
\hline 4. & ain & 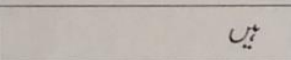 & أين \\
\hline 5. & een & $\omega^{2}$ & ! \\
\hline
\end{tabular}

